\title{
Risk Factors Associated with Endometrial Pathology in Premenopausal Breast Cancer Patients Treated with Tamoxifen
}

\author{
Maria Lee ${ }^{1,2 *}$, Jinlan Piao ${ }^{1 *}$, and Myung Jae Jeon ${ }^{1,2}$ \\ ${ }^{1}$ Department of Obstetrics and Gynecology, Seoul National University College of Medicine, Seoul; \\ ${ }^{2}$ Department of Obstetrics and Gynecology, Seoul National University Hospital, Seoul, Korea
}

Purpose: To evaluate factors associated with endometrial pathology during tamoxifen use in premenopausal breast cancer (BC) patients.

Materials and Methods: We reviewed the medical records of premenopausal BC patients treated with tamoxifen who underwent endometrial biopsy with or without hysteroscopy. Clinical characteristics were compared between women with endometrial pathology (endometrial hyperplasia or cancer) and those with normal histology or endometrial polyps.

Results: Among 284 endometrial biopsies, endometrial hyperplasia was diagnosed in 7 patients (2.5\%), endometrial cancer was diagnosed in 5 patients (1.8\%), normal histology was noted in 146 patients (51.4\%), and endometrial polyp was present in 114 patients $(40.1 \%)$. When comparing women with endometrial cancer $(n=5)$ to women with normal histology, abnormal uterine bleeding was more common $(p=0.007)$, and endometrial thickness was greater $(p=0.007)$ in women with endometrial cancer. Chemotherapy for $\mathrm{BC}$ was also more common in patients with endometrial cancer $(p=0.037)$. When comparing women with endometrial polyps and those with endometrial hyperplasia or cancer, the presence of abnormal uterine bleeding was more common in patients with endometrial hyperplasia or cancer $(p<0.001)$; however, tamoxifen duration and endometrial thickness did not differ significantly between the two groups.

Conclusion: In premenopausal BC patients treated with tamoxifen, abnormal uterine bleeding, increased endometrial thickness, and chemotherapy for $\mathrm{BC}$ were associated with the occurrence of endometrial cancer. These findings may provide useful information for gynecologic surveillance and counseling during tamoxifen treatment in premenopausal BC patients.

Key Words: Endometrial polyps, hysteroscopy, breast cancer, tamoxifen, premenopausal

\section{INTRODUCTION}

Approximately 17 million new cases of breast cancer (BC) each

Received: December 3, 2019 Revised: February 11, 2020

Accepted: February 27, 2020

Corresponding author: Myung Jae Jeon, MD, PhD, Department of Obstetrics and Gynecology, Seoul National University College of Medicine, Seoul National University Hospital, 101 Daehak-ro, Jongno-gu, Seoul 03080, Korea.

Tel: 82-2-2072-1916, Fax: 82-2-762-3599, E-mail: jeonmj@snu.ac.kr

${ }^{*}$ Maria Lee and Jinlan Piao contributed equally to this work.

-The authors have no potential conflicts of interest to disclose.

(C) Copyright: Yonsei University College of Medicine 2020

This is an Open Access article distributed under the terms of the Creative Commons Attribution Non-Commercial License (https://creativecommons.org/licenses/ by-nc/4.0) which permits unrestricted non-commercial use, distribution, and reproduction in any medium, provided the original work is properly cited. year are expected to occur worldwide, and BC is the second most common cancer among Korean women. ${ }^{1}$ In Korea, 46.6\% of all women newly diagnosed with BC during 2012 were premenopausal, and the largest proportion of newly diagnosed BC patients that year were aged between 40 and 49 years $(34.5 \%){ }^{1}$ The proportions of both estrogen receptor (ER)-positive and progesterone receptor (PR)-positive BC patients have increased steadily since 2002 , from $58.2 \%$ in 2002 to $74.1 \%$ in 2014 (27.3\% increase) for ER-positive disease and from 50.7\% in 2002 to $62.4 \%$ in 2014 ( $23.1 \%$ increase, $p=0.001$ ) for PR-positive BC. ${ }^{2}$

Unquestionably, tamoxifen use as an adjuvant endocrine therapy has been effective in reducing recurrence and increasing survival of ER-positive BC patients. ${ }^{3,4}$ Recently, several studies have shown that continuing tamoxifen therapy for 10 years is associated with lower recurrence and mortality rates than 
treatment for 5 years in patients with ER-positive BC. ${ }^{5,6}$ With the growing number of younger BC patients, the use of tamoxifen, as well as concurrent gonadotropin-releasing hormone ( $\mathrm{GnRH})$ agonists, has increased. As a result, surveillance for endometrial pathologies in younger BC patients is an important issue.

While older age, menopausal status, longer duration of tamoxifen use, and the presence of abnormal uterine bleeding are known risk factors for endometrial cancer in tamoxifen-treated women, few studies have evaluated risk factors for endometrial pathology in premenopausal women treated with tamoxifen. Moreover, all women (both before and after menopause) involve an increased risk of developing endometrial polyps secondary to tamoxifen use, ${ }^{7}$ and it has been suggested that postmenopausal patients treated for more than 2 years have a higher frequency of endometrial pathologies. ${ }^{8}$ Considering the high proportion of premenopausal BC women and their unique characteristics in Korea, it is critical to define the characteristics of tamoxifen-treated premenopausal women and identify any potential endometrial effects that may arise from this treatment. To date, endometrial surveillance strategies are not age based. Thus, the purpose of the present study was to investigate the prevalence of endometrial pathologic lesions in premenopausal tamoxifen-treated BC patients and to evaluate risk factors associated with the development of these lesions.

\section{MATERIALS AND METHODS}

This study included all premenopausal BC women treated with adjuvant tamoxifen who had undergone ultrasonography and endometrial biopsy with or without hysteroscopy at Seoul National University Hospital from January 2013 through December 2016.

We excluded patients with any of the following characteristics from our analysis: 1) lack of regular menstrual cycles or menstruation within 3 months before the first day of chemotherapy; 2) no tamoxifen treatment; 3) serum follicle-stimulating hormone level $>40 \mathrm{mIU} / \mathrm{mL}$ at the outpatient visit; and 4) insufficient clinical and/or pathologic data. Transvaginal or transrectal ultrasonography was performed regardless of the menstrual cycle day. All patients had undergone BC surgery and were treated postoperatively with tamoxifen. Other treatments included a GnRH agonist, chemotherapy, and/or radiotherapy. This retrospective study was performed with approval from the Institutional Review Board of Seoul National University Hospital (No.1911-159-1082).

The usual clinical approach at our institution is as follows. Most asymptomatic patients treated with tamoxifen undergo yearly ultrasonography examinations. If a patient has abnormal bleeding with or without endometrial thickening, we perform hysteroscopic evaluation. Additionally, endometrial biopsy is performed if endometrial thickness is greater than $10 \mathrm{~mm}$ or if a new or enlarging polypoid lesion is observed, even in the absence of symptoms.

As previously described, ${ }^{9}$ diagnostic hysteroscopy was performed in the outpatient clinic using a 5-mm hysteroscope (Richard Wolf Medical Instruments Corp., Vernon Hills, IL, USA). If an endometrial lesion was identified, immediate resection of the lesion was performed. Deferred inpatient surgical hysteroscopy was performed in patients unable to tolerate the outpatient procedure and in patients with cervical stenosis or large lesions. A 10-mm resectoscope (Karl Storz Endoskope, Tuttlingen, Germany) was used for surgical resection of endometrial lesions, and Urosol (CJ Cheiljedang, Seoul, Korea) was used as the distension fluid. Hysteroscopic findings and clinicopathologic data were obtained retrospectively from the medical records. Information regarding the following variables were collected: age, body mass index (BMI), parity, stage, duration of tamoxifen treatment, other nonsurgical treatment (chemotherapy, radiotherapy, GnRH agonist), presence of menstruation, occurrence of chemotherapy-induced amenorrhea, endometrial thickness, and presence of abnormal uterine bleeding.

Statistical analysis was performed using IBM SPSS ver. 23.0 software (IBM Corp., Armonk, NY, USA). Age, BMI, parity, duration of tamoxifen treatment, and endometrial thickness were compared using Student's t-test. Stage, history of chemotherapy treatment, and presence of abnormal uterine bleeding were compared using the chi-square test. Univariate and multivariate analyses were performed to identify risk factors associated with the presence of endometrial pathology (endometrial hyperplasia or endometrial cancer). Two-sided $p$ values less than 0.05 were considered statistically significant.

\section{RESULTS}

A total of 284 patients were included in this study. Table 1 shows the patients' characteristics. Their mean age was 45 years (range, 27-57) and mean BMI was $22.5 \pm 3.8 \mathrm{~kg} / \mathrm{m}^{2}$. The mean duration of tamoxifen treatment was 1023.9 days (2.8 years). Most patients were diagnosed with $\mathrm{BC}$ at an early stage: stage $0,8.5 \%$ $(\mathrm{n}=24)$; stage I, 55.6\% ( $\mathrm{n}=158)$; stage II, $29.9 \%(\mathrm{n}=85)$; and stage III, $6.2 \%(\mathrm{n}=17)$. Moreover, $51.4 \%$ of patients received cytotoxic chemotherapy before or after breast surgery; $95.8 \%$ of these patients experienced chemotherapy-induced amenorrhea. Mean endometrial thickness on ultrasonography was $11.5 \pm 5.2 \mathrm{~mm}$, and $32.7 \%$ of patients experienced abnormal uterine bleeding.

The final histologic outcomes of 284 endometrial biopsies are presented in Table 1. Endometrial polyp was the most common abnormal histology ( $n=114,40.1 \%$ of biopsies). Endometrial hyperplasia was present in 7 patients $(2.5 \%)$, and endometrial cancer was observed in 5 patients (1.8\%). Atypia was present in all biopsies exhibiting complex endometrial hyperplasia.

Table 2 shows the factors potentially associated with the presence of endometrial pathology in our tamoxifen-treated pa- 
tients. A histologic diagnosis of endometrial hyperplasia or cancer was not significantly associated with age, BMI, parity, duration of tamoxifen use, treatment with chemotherapy, or

Table 1. Clinical Characteristics and Histologic Results of the Study Subjects $(\mathrm{n}=284$ )

\begin{tabular}{lc}
\hline \multicolumn{1}{c}{ Variables } & Value \\
\hline Clinical characteristics & \\
\hline Age (yr) & $45.0 \pm 4.7$ \\
\hline Body mass index $\left(\mathrm{kg} / \mathrm{m}^{2}\right)$ & $22.5 \pm 3.8$ \\
\hline Parity, $\mathrm{n}$ & $1.4 \pm 1.0$ \\
\hline Tamoxifen duration (days) & $1023.9 \pm 784.5$ \\
\hline Stage & \\
Stage 0 & $24(8.5)$ \\
Stage I & $158(55.6)$ \\
Stage II & $85(29.9)$ \\
Stage III & $17(6.2)$ \\
\hline Chemotherapy & $146(51.4)$ \\
\hline Gonadotropin-releasing hormone agonist & $68(23.9)$ \\
\hline Radiotherapy & $200(70.4)$ \\
\hline Endometrial thickness (mm) & $11.5 \pm 5.2$ \\
\hline Abnormal uterine bleeding & $93(32.7)$ \\
\hline Histologic results & \\
\hline No pathology & $146(51.4)$ \\
\hline Endometrial polyp & $114(40.1)$ \\
\hline Submucosal myoma & $12(4.2)$ \\
\hline Endometrial hyperplasia & $7(2.5)$ \\
Simple hyperplasia without atypia & $2(0.7)$ \\
Complex hyperplasia with atypia & $5(1.8)$ \\
\hline Endometrial cancer & $5(1.8)$ \\
\hline
\end{tabular}

Values are presented as mean \pm standard deviation or $\mathrm{n}(\%)$. endometrial thickness. Meanwhile, however, the rate of abnormal uterine bleeding was significantly higher in patients with endometrial hyperplasia or cancer than in those with normal endometrium ( $p=0.003$ ). Moreover, a histologic diagnosis of endometrial cancer was significantly associated with the presence of abnormal uterine bleeding, treatment with chemotherapy, and endometrial thickness. The rate of abnormal uterine bleeding was significantly lower in women with endometrial polyps than in those with endometrial pathology $(p<0.001)$ (Supplementary Table 1, only online). In addition, treatment with chemotherapy, abnormal uterine bleeding, and endometrial thickness were associated with endometrial cancer. Age, BMI, and duration of tamoxifen use did not differ between women with endometrial hyperplasia or cancer and women with endometrial polyps.

Univariate and multivariate analyses were performed to explore associations between endometrial pathology and the following potential risk factors: age, duration of tamoxifen use, endometrial thickness, presence of abnormal uterine bleeding, and treatment with chemotherapy. The results showed that only abnormal uterine bleeding was significantly associated with the presence of endometrial hyperplasia or cancer (hazard ratio, 7.3; 95\% confidence interval, 1.417-37.668; $p=0.017$ ) (Table 3 ).

We also reviewed six previous studies that assessed the endometrium in premenopausal women receiving tamoxifen treatment. The characteristics and results of these studies, which included 1450 women in total, are presented in Table 4. Four of these studies reported risk factors associated with endometrial changes. Two studies identified symptoms (uterine bleeding) as a risk factor, and one study identified duration of tamoxifen treatment as a risk factor.

Table 2. Comparisons of Characteristics between Women with Endometrial Pathology (Hyperplasia or Cancer) and Women with Normal Endometrium at the Time of Biopsy

\begin{tabular}{|c|c|c|c|c|c|}
\hline Characteristics & Normal ( $n=146)$ & Hyperplasia or cancer ( $n=12$ ) & $p$ value & Cancer $(n=5)$ & $p$ value \\
\hline Age at biopsy (yr) & $44.7 \pm 4.9$ & $47.1 \pm 5.3$ & 0.111 & $47.8 \pm 5.6$ & 0.169 \\
\hline Body mass index $\left(\mathrm{kg} / \mathrm{m}^{2}\right)$ & $22.7 \pm 4.4$ & $22.9 \pm 2.8$ & 0.892 & $22.4 \pm 3.4$ & 0.891 \\
\hline Parity, n & $1.5 \pm 1.0$ & $1.4 \pm 1.1$ & 0.748 & $0.8 \pm 0.8$ & 0.117 \\
\hline Tamoxifen duration (days) & $961.2 \pm 682.7$ & $1307.1 \pm 752.8$ & 0.096 & $1567.1 \pm 1092.0$ & 0.058 \\
\hline Chemotherapy & $69(47.3)$ & $7(58.3)$ & 0.711 & $5(100.0)$ & 0.037 \\
\hline Abnormal uterine bleeding & $58(39.7)$ & $10(83.3)$ & 0.003 & $5(100.0)$ & 0.007 \\
\hline Endometrial thickness (mm) & $11.0 \pm 5.5$ & $13.8 \pm 5.3$ & 0.091 & $17.9 \pm 5.7$ & 0.007 \\
\hline
\end{tabular}

Values are presented as mean \pm standard deviation or $\mathrm{n}(\%)$.

Table 3. Univariate and Multivariate Analysis of Risk Factors for Endometrial Hyperplasia or Endometrial Cancer

\begin{tabular}{|c|c|c|c|c|c|}
\hline \multirow{2}{*}{ Variable } & \multicolumn{2}{|c|}{ Univariate analysis } & \multicolumn{3}{|c|}{ Multivariate analysis } \\
\hline & Hazard ratio & $p$ value & Hazard ratio & $95 \% \mathrm{Cl}$ & $p$ value \\
\hline Age $\geq 45$ years & 1.6 & 0.518 & 1.1 & $0.248-4.860$ & 0.902 \\
\hline Duration of tamoxifen use $\geq 3$ years & 2.6 & 0.147 & 2.2 & $0.545-8.859$ & 0.268 \\
\hline Endometrial thickness $\geq 12 \mathrm{~mm}$ & 2.2 & 0.251 & 2.8 & $0.686-11.094$ & 0.153 \\
\hline Abnormal uterine bleeding & 6.1 & 0.026 & 7.3 & $1.417-37.668$ & 0.017 \\
\hline Chemotherapy & 2.1 & 0.299 & 2.4 & $0.551-10.075$ & 0.248 \\
\hline
\end{tabular}

$\mathrm{Cl}$, confidence interval. 
Table 4. Previous Studies Involving Endometrial Assessments in Premenopausal Women Receiving Tamoxifen for Breast Cancer

\begin{tabular}{|c|c|c|c|c|c|c|}
\hline $\begin{array}{l}\text { First author } \\
\text { (year) }\end{array}$ & Country & Study design & $\begin{array}{l}\text { No. of patients } \\
\text { treated with } \\
\text { tamoxifen }\end{array}$ & $\begin{array}{c}\text { Endometrial outcomes } \\
\text { assessed }\end{array}$ & $\begin{array}{l}\text { No. of endometrial } \\
\text { lesions in patients } \\
\text { treated with tamoxifen }\end{array}$ & Risk factors \\
\hline $\begin{array}{l}\text { Swerdlow and } \\
\text { Jones }^{23} \text { (2005) }\end{array}$ & UK & Case-control & 673 & Endometrial cancer & 69 & $\begin{array}{l}\text { Tamoxifen use, duration of tamoxifen } \\
\text { treatment, abdominal/pelvis } \\
\text { radiotherapy }\end{array}$ \\
\hline $\begin{array}{l}\text { d'Arailh, et al. }{ }^{24} \\
\text { (2007) }\end{array}$ & France & $\begin{array}{l}\text { Retrospective } \\
\text { review }\end{array}$ & 152 & $\begin{array}{l}\text { Endometrial hyperplasia (3/19) } \\
\text { Endometrial polyps (11) }\end{array}$ & 14 & $\begin{array}{l}\text { Uterine bleeding (associated with } \\
\text { endometrial hyperplasia) }\end{array}$ \\
\hline $\begin{array}{l}\text { Kim, et al. }{ }^{25} \\
(2008)\end{array}$ & Korea & $\begin{array}{l}\text { Retrospective } \\
\text { review }\end{array}$ & 155 & $\begin{array}{l}\text { Endometrial hyperplasia (1) } \\
\text { Endometrial polyps (6) }\end{array}$ & 7 & ND \\
\hline $\begin{array}{l}\mathrm{Gu} \text {, et al. }{ }^{26} \\
(2012)\end{array}$ & China & Case-control & 240 & $\begin{array}{l}\text { Endometrial hyperplasia (15) } \\
\text { Endometrial polyps (2) }\end{array}$ & 17 & ND \\
\hline $\begin{array}{l}\text { Yang, et al. }{ }^{27} \\
(2013)\end{array}$ & China & Prospective & 110 & Endometrial thickness & NA & $\begin{array}{l}\text { Additional use of goserelin } \\
\text { (associated with a thinner } \\
\text { endometrium) }\end{array}$ \\
\hline $\begin{array}{l}\text { Jeon, et al. }{ }^{9} \\
(2017)\end{array}$ & Korea & $\begin{array}{l}\text { Retrospective } \\
\text { review }\end{array}$ & 120 & $\begin{array}{l}\text { Endometrial cancer (1) } \\
\text { Endometrial hyperplasia (2) } \\
\text { Endometrial polyps (50) }\end{array}$ & 53 & $\begin{array}{l}\text { Uterine bleeding (associated with } \\
\text { endometrial polyps) }\end{array}$ \\
\hline
\end{tabular}

NA, not applicable; ND, not determined.

\section{DISCUSSION}

In this study, we found that the presence of abnormal uterine bleeding was the most important factor associated with the presence of endometrial pathology (hyperplasia or cancer) and that abnormal uterine bleeding, treatment with chemotherapy, and increased endometrial thickness on ultrasonography were risk factors associated with endometrial cancer in premenopausal women with $\mathrm{BC}$ treated with tamoxifen.

Previous studies have reported that tamoxifen is associated with dose- and time-dependent increases in the risks of endometrial proliferation, polyps, hyperplasia, and invasive carcinoma, as well as uterine sarcoma. ${ }^{7,10-14}$ In the current study, the mean durations of tamoxifen use in women with normal endometrium and endometrial hyperplasia or cancer were 2.6 and 3.5 years, respectively. However, duration of tamoxifen use was not associated with the presence of endometrial pathology. Previous studies reported significantly increased risks of endometrial cancer after 2 years of tamoxifen use. ${ }^{15}$ Large prospective research is required to clarify the role of tamoxifen as a potential risk factor for the development of endometrial cancer.

Menopausal status and older age have previously been reported to increase the risk of endometrial cancer in tamoxifen users, ${ }^{16-18}$ whereas premenopausal women exhibit a lower risk of endometrial cancer, even if they are symptomatic. ${ }^{19}$ Although the actual risk of endometrial pathology in premenopausal women was not assessed in the present study, our findings suggest that appropriate surveillance is important in premenopausal tamoxifen users.

Another well-known risk factor for both breast and endometrial cancers is obesity. ${ }^{20}$ However, BMI was not associated with the presence of endometrial pathology in our study. The over- all lower BMI in Asian women, compared with Western women, and the small number of patients with endometrial pathology might explain the discrepancy between our results and those of previous studies.

Endometrial polyps are the most common uterine pathology in postmenopausal tamoxifen-treated BC patients. Howev$\mathrm{er}$, there is limited research on the risk of malignant transformation of endometrial polyps in premenopausal tamoxifen-treated $\mathrm{BC}$ patients. We found that the prevalence of endometrial polyps in premenopausal women receiving tamoxifen was $40.7 \%$, and the majority of these patients were asymptomatic. Moreover, the presence of abnormal uterine bleeding was significantly higher in patients with endometrial hyperplasia and cancer than in those with endometrial polyps.

Evaluation of endometrial thickness by ultrasonography is the most commonly used tool for gynecologic surveillance in tamoxifen-treated BC patients. However, the diagnostic accuracy of this method is not particularly great, even when setting the cut-off value at $10 \mathrm{~mm} .{ }^{21,22}$ Establishing an appropriate cutoff value in premenopausal women is difficult because the appearance of the endometrium varies in relation to the menstrual cycle. Therefore, endometrial appearance or presence of abnormal uterine bleeding should be considered in conjunction with endometrial thickness when performing gynecologic surveillance in women treated with tamoxifen.

According to guidelines from the American Congress of Obstetricians and Gynecologists, premenopausal patients with a history of tamoxifen use involve no known increased risk of endometrial cancer and do not require any further monitoring beyond routine gynecologic examinations. ${ }^{7}$ However, resection of endometrial polyps diagnosed by ultrasonography in postmenopausal tamoxifen-treated BC patients is recommended 
because of the relatively high risk of malignancy in these women. Although the potential for malignant transformation is lower in premenopausal patients than in postmenopausal BC patients, we suggest that removal of endometrial polyps ought to be considered in premenopausal tamoxifen-treated BC patients. This may be important for patients with a relatively thick endometrium (e.g., $\geq 12 \mathrm{~mm}$ ) and abnormal uterine bleeding, as these factors further increase the probability of endometrial cancer.

We identified six previous studies involving endometrial assessments in premenopausal women treated with tamoxifen. ${ }^{9,23-27}$ Most were retrospective or case-control studies. The single prospective study assessed only endometrial thickness and did not report the presence of, or risk factors for, endometrial pathology. Very limited evidence from the other five studies suggested that abnormal uterine bleeding and tamoxifen duration are risk factors for endometrial hyperplasia or cancer in premenopausal women treated with tamoxifen.

There are a few limitations to this study. Because this was a retrospective study, endometrial thickness results were not available for the majority of patients before starting tamoxifen treatment. However, most of our asymptomatic patients treated with tamoxifen underwent annual ultrasonography examinations after beginning therapy, often with subsequent hysteroscopic evaluation. Another limitation of the study was that the number of patients with endometrial pathology was insufficient to allow estimation of endometrial thickness cut-off values for predicting the development of endometrial pathology. However, the endometrium was significantly thicker (mean, $17.9 \mathrm{~mm}$ ) in patients with endometrial cancer than in those endometrial polyps or hyperplasia. To confirm our findings, it will be necessary to conduct a large-scale, multicenter study assessing endometrial pathology in premenopausal BC patients treated with tamoxifen use.

In conclusion, our study demonstrated that the presence of abnormal uterine bleeding, but not age, BMI, or duration of tamoxifen use, may be the most important factor associated with the occurrence of endometrial hyperplasia or cancer during tamoxifen use in premenopausal women with BC. This finding provides useful information for endometrial surveillance and counseling during tamoxifen use in premenopausal BC patients.

\section{AUTHOR CONTRIBUTIONS}

Conceptualization: Maria Lee and Myung Jae Jeon. Data curation: Maria Lee and Jinlan Piao. Formal analysis: Maria Lee and Jinlan Piao. Investigation: Maria Lee and Myung Jae Jeon. Methodology: Maria Lee and Jinlan Piao. Project administration: Maria Lee and Myung Jae Jeon. Resources: Maria Lee and Myung Jae Jeon. Software: Maria Lee, Jinlan Piao, and Myung Jae Jeon. Supervision: Myung Jae Jeon. Validation: Maria Lee and Jinlan Piao. Visualization: Maria Lee and Jinlan Piao. Writing_original draft: Maria Lee, Jinlan Piao, and Myung Jae Jeon. Writing_review \& editing: Maria Lee, Jinlan Piao, and Myung Jae Jeon. Approval of final manuscript: all authors.

\section{ORCID iDs}

$\begin{array}{ll}\text { Maria Lee } & \text { https://orcid.org/0000-0002-8017-3176 } \\ \text { Jinlan Piao } & \text { https://orcid.org/0000-0001-5433-0097 } \\ \text { Myung Jae Jeon } & \text { https://orcid.org/0000-0001-5582-1488 }\end{array}$

\section{REFERENCES}

1. Kim Z, Min SY, Yoon CS, Jung KW, Ko BS, Kang E, et al. The basic facts of Korean breast cancer in 2012: results from a nationwide survey and breast cancer registry database. J Breast Cancer 2015; 18:103-11.

2. Park EH, Min SY, Kim Z, Yoon CS, Jung KW, Nam SJ, et al. Basic facts of breast cancer in Korea in 2014: the 10-year overall survival progress. J Breast Cancer 2017;20:1-11.

3. Figg WD 2nd, Cook K, Clarke R. Aromatase inhibitor plus ovarian suppression as adjuvant therapy in premenopausal women with breast cancer. Cancer Biol Ther 2014;15:1586-7.

4. LE Donne M, Alibrandi A, Ciancimino L, Azzerboni A, Chiofalo B, Triolo O. Endometrial pathology in breast cancer patients: effect of different treatments on ultrasonographic, hysteroscopic and histological findings. Oncol Lett 2013;5:1305-10.

5. Davies C, Pan H, Godwin J, Gray R, Arriagada R, Raina V, et al. Longterm effects of continuing adjuvant tamoxifen to 10 years versus stopping at 5 years after diagnosis of oestrogen receptor-positive breast cancer: ATLAS, a randomised trial. Lancet 2013;381:805-16.

6. Goss PE. Preventing relapse beyond 5 years: the MA.17 extended adjuvant trial. Semin Oncol 2006;33(2 Suppl 7):S8-12.

7. Sismondi P, Biglia N, Volpi E, Giai M, de Grandis T. Tamoxifen and endometrial cancer. Ann N Y Acad Sci 1994;734:310-21.

8. Cohen I, Altaras MM, Shapira J, Tepper R, Rosen DJ, Cordoba M, et al. Time-dependent effect of tamoxifen therapy on endometrial pathology in asymptomatic postmenopausal breast cancer patients. Int J Gynecol Pathol 1996;15:152-7.

9. Jeon SJ, Lee JI, Lee M, Kim HS, Kim JW, Park NH, et al. Endometrial polyp surveillance in premenopausal breast cancer patients using tamoxifen. Obstet Gynecol Sci 2017;60:26-31.

10. Cheng WF, Lin HH, Torng PL, Huang SC. Comparison of endometrial changes among symptomatic tamoxifen-treated and nontreated premenopausal and postmenopausal breast cancer patients. Gynecol Oncol 1997;66:233-7.

11. Saccardi C, Gizzo S, Patrelli TS, Ancona E, Anis O, Di Gangi S, et al. Endometrial surveillance in tamoxifen users: role, timing and accuracy of hysteroscopic investigation: observational longitudinal cohort study. Endocr Relat Cancer 2013;20:455-62.

12. Berlière $M$, Charles A, Galant $C$, Donnez J. Uterine side effects of tamoxifen: a need for systematic pretreatment screening. Obstet Gynecol 1998;91:40-4.

13. Fisher B, Costantino JP, Redmond CK, Fisher ER, Wickerham DL, Cronin WM. Endometrial cancer in tamoxifen-treated breast cancer patients: findings from the National Surgical Adjuvant Breast and Bowel Project (NSABP) B-14. J Natl Cancer Inst 1994;86:527-37.

14. Braithwaite RS, Chlebowski RT, Lau J, George S, Hess R, Col NF. Meta-analysis of vascular and neoplastic events associated with tamoxifen. J Gen Intern Med 2003;18:937-47.

15. Fornander T, Rutqvist LE, Cedermark B, Glas U, Mattsson A, Silfverswärd C, et al. Adjuvant tamoxifen in early breast cancer: occurrence of new primary cancers. Lancet 1989;1:117-20.

16. Cohen I, Bernheim J, Azaria R, Tepper R, Sharony R, Beyth Y. Malignant endometrial polyps in postmenopausal breast cancer tamoxifen-treated patients. Gynecol Oncol 1999;75:136-41.

17. Iqbal J, Ginsburg OM, Wijeratne TD, Howell A, Evans G, Sestak I, 
et al. Endometrial cancer and venous thromboembolism in women under age 50 who take tamoxifen for prevention of breast cancer: a systematic review. Cancer Treat Rev 2012;38:318-28.

18. Garuti G, Cellani F, Centinaio G, Sita G, Nalli G, Luerti M. Baseline endometrial assessment before tamoxifen for breast cancer in asymptomatic menopausal women. Gynecol Oncol 2005;98:63-7.

19. Pennant ME, Mehta R, Moody P, Hackett G, Prentice A, Sharp SJ, et al. Premenopausal abnormal uterine bleeding and risk of endometrial cancer. BJOG 2017;124:404-11.

20. Bergman L, Beelen ML, Gallee MP, Hollema H, Benraadt J, van Leeuwen FE. Risk and prognosis of endometrial cancer after tamoxifen for breast cancer. Lancet 2000;356:881-7.

21. Gerber B, Krause A, Müller H, Reimer T, Külz T, Makovitzky J, et al. Effects of adjuvant tamoxifen on the endometrium in postmenopausal women with breast cancer: a prospective long-term study using transvaginal ultrasound. J Clin Oncol 2000;18:3464-70.

22. Fung MF, Reid A, Faught W, Le T, Chenier C, Verma S, et al. Prospective longitudinal study of ultrasound screening for endometrial abnormalities in women with breast cancer receiving tamoxifen. Gynecol Oncol 2003;91:154-9.

23. Swerdlow AJ, Jones ME; British Tamoxifen Second Cancer Study
Group. Tamoxifen treatment for breast cancer and risk of endometrial cancer: a case-control study. J Natl Cancer Inst 2005;97: 375-84.

24. d'Arailh AS, Michy T, Pioud R, Dravet F, Classe JM. [Uterine abnormalities in non menopausal women who received tamoxifen for breast cancer adjuvant therapy]. Gynecol Obstet Fertil 2007; 35:1215-9.

25. Kim HS, Jeon YT, Kim YB. The effect of adjuvant hormonal therapy on the endometrium and ovary of breast cancer patients. J Gynecol Oncol 2008;19:256-60.

26. Gu R, Jia W, Zeng Y, Rao N, Hu Y, Li S, et al. A comparison of survival outcomes and side effects of toremifene or tamoxifen therapy in premenopausal estrogen and progesterone receptor positive breast cancer patients: a retrospective cohort study. BMC Cancer 2012;12:161.

27. Yang H, Zong X, Yu Y, Shao G, Zhang L, Qian C, et al. Combined effects of goserelin and tamoxifen on estradiol level, breast density, and endometrial thickness in premenopausal and perimenopausal women with early-stage hormone receptor-positive breast cancer: a randomised controlled clinical trial. Br J Cancer 2013; 109:582-8. 